\title{
Physical Stability and HPLC Analysis of Indian Kudzu (Pueraria tuberosa Linn.) Fortified Milk
}

\author{
Subha Rastogi, ${ }^{1}$ Antariksha Katara, ${ }^{1}$ Madan M. Pandey, ${ }^{1}$ Sumit Arora, ${ }^{2}$ \\ R. R. B. Singh, ${ }^{2}$ and A. K. S. Rawat ${ }^{1}$ \\ ${ }^{1}$ CSIR-National Botanical Research Institute, Lucknow, India \\ ${ }^{2}$ National Dairy Research Institute, Karnal, Haryana, India \\ Correspondence should be addressed to A. K. S. Rawat; rawataks@rediffmail.com
}

Received 31 January 2013; Revised 25 March 2013; Accepted 1 April 2013

Academic Editor: Weena Jiratchariyakul

Copyright (C) 2013 Subha Rastogi et al. This is an open access article distributed under the Creative Commons Attribution License, which permits unrestricted use, distribution, and reproduction in any medium, provided the original work is properly cited.

\begin{abstract}
Functional foods provide health benefit beyond basic nutrition. Functional foods fortified with plant ingredients are well known. Ayurveda (Indian System of Medicine) has found several ways in which the medicinal benefits of herbs can be conveyed via certain foods as carriers. Milk is one such carrier which has been effectively used to deliver phytochemicals for targeted health benefits. Indian Kudzu or Pueraria tuberosa Linn. (Fabaceae) is an important medicinal plant of Ayurveda, and experiments suggest that it enhances the health benefits of milk when taken with milk as a carrier. Different milk combinations with $P$. tuberosa were prepared by homogenizing pasteurized toned milk with its ethanolic and hot water extracts and their stability with reference to $\mathrm{pH}$ and coagulation was studied over a period of 15 days. The combinations were also analyzed for puerarin, the major isoflavone C-glucoside present in P. tuberosa, through high-performance liquid chromatography using photo diode array detector. It was observed that there was no precipitate formation and the $\mathrm{pH}$ also did not change during the study period indicating their physical stability under the experimental conditions. Also there was no significant change in the content of puerarin during the study period, thereby indicating the chemical stability of the samples. These studies will be useful for developing milk nutraceuticals fortified with Indian Kudzu which has the potential to be included as an ingredient in health and functional foods.
\end{abstract}

\section{Introduction}

The use of botanicals in foodstuffs is well established. It includes use as vegetables, fruits, herbs, and botanical food supplements. While medicinal products are intended to prevent or treat a disease or modify the way in which the body functions, food supplements and nutraceuticals are intended to complement the diet with substances possessing healthmaintenance or -promoting properties [1]. Food industries have rather high demand for the products that meet the consumer's demand for a healthy lifestyle. There are many companies already capitalizing on growing consumer acceptance of food and beverages containing herbal extracts [2]. Ayurveda (Indian System of Medicine) has found several ways in which the medicinal benefits of herbs could be conveyed via certain foods as carriers. Milk is one such carrier which has been effectively used to deliver phytochemicals for targeted health benefits in the traditional Indian system of medical science. Milk is also one of the most widely consumed foods in the world and is an ideal vehicle for the fortification with these nutraceuticals.

Indian Kudzu or Pueraria tuberosa Linn. (Fabaceae) is an important medicinal plant of the Indian traditional system of medicine, that is, Ayurveda, and is mentioned in the Ayurvedic Pharmacopoeia of India under the name of Vidari. Powder of tubers of P. tuberosa (PT), commonly known as Indian Kudzu or Vidarikand in Hindi [3], is recommended for clinical use in the dose of 2-6 g/adult person [4]. It is used in traditional medicine as a fertility control agent and as an aphrodisiac, cardiotonic, diuretic and galactogogue. It has exhibited antihyperglycemic, antihyperlipidemic, antifertility in male rats, hepatoprotective, and anti-implantation activities [5-8]. It is a constituent of various formulations used as nutritive, diuretic, expectorants, and for the management of rheumatism, fever, and bronchitis $[4,9]$. P. tuberosa tubers are rich in isoflavonoids 
and the important phytoconstituents are puerarin, daidzein, genistein, puetuberosanol, and tuberosin [10-13]. During the past decade, interest in these isoflavonoids has increased considerably because of the beneficial effects proposed by epidemiologists, nutritionists, and food manufacturers [14]. These isoflavonoids could interact with milk proteins, namely, bovine serum albumin [15], casein micelle [16], and $\beta$-lactoglobulin [17] as has been reported in case of certain food and drug preparation containing soya isoflavonoids. In vivo studies further revealed that these interactions often lead to reduction in lipid oxidation and improvement in antioxidant properties which are of great significance from health point of view.

Recently, we have investigated the in vivo immunomodulatory and antioxidative effect of $P$. tuberosa with milk as the carrier. The results suggested that $P$. tuberosa contained active compounds that improved the therapeutic properties of milk. The milk supplemented with $P$. tuberosa extracts exhibited immunostimulatory and antioxidative properties [18]. Studies have also been carried out to determine the effect of added herb extracts on oxidative stability of ghee during accelerated oxidation condition and it was found that the ethanolic extract of vidarikand had the maximum antioxidant activity among all the herbs [19].

Since the health benefits of the nutraceuticals or functional foods containing different botanicals are due to the presence of the phytoconstituents of the added botanicals, it is important to have a biological marker and also to be able to associate that biological marker with the quality of life. Puerarin is the major constituent of Pueraria species. It is prescribed to treat coronary heart disease and alcoholism. It may prevent cancer, act as an antioxidant, lower serum cholesterol, and have antithrombotic and antiallergic activities $[5,20,21]$. Puerarin has exhibited antihyperglycemic effect in streptozotocin-induced diabetic rats and possesses estrogen-like biological activities. Recent studies showed that puerarin protects different cell types from damage caused by a variety of toxic stimuli. Data also suggest that puerarin might be beneficial for the treatment of Alzheimer's disease [22].

Several methods have been reported for the identification and analysis of puerarin [23]. But, to the best of our knowledge, no work on identification of $P$. tuberosa in milk nutraceuticals has been previously reported. Thus, continuing with our studies on herb-(P. tuberosa) milk model systems, the present work was carried out to study the stability of milk fortified with Indian Kudzu with reference to its $\mathrm{pH}$ and coagulation as well as to analyze Kudzufortified milk for puerarin, the major isoflavone $\mathrm{C}$-glucoside present in $P$. tuberosa, through high-performance liquid chromatography using photo diode array detector.

\section{Materials and Methods}

2.1. Chemicals and Reagents. Puerarin was obtained from Sigma-Aldrich (St. Louis, MO, USA). HPLC-grade methanol and water were obtained from Merck (Darmstadt, Germany). Whatman (Florham Park, NJ) No. 1 filter paper was used for filtration of the samples. Other chemicals and solvents were purchased from Merck Chemicals, Mumbai, India.
2.2. Plant Material. Tubers of P. tuberosa were collected from the Uttarakhand region. The sample was identified and authenticated by Dr. A. K. S. Rawat, by comparison with a reference sample preserved in the Herbarium department of NBRI. They were deposited (specimen number $\mathrm{NBR} / \mathrm{PH} / 227348$ ) in the departmental herbal drug museum of the Pharmacognosy Division, National Botanical Research Institute, Lucknow, India, for future reference.

2.3. Preparation of Ethanolic and Hot Water Extracts. The coarse air-dried, $\left(40^{\circ}-50^{\circ} \mathrm{C}\right)$, powdered tubers $(500 \mathrm{~g}$ each) of $P$. tuberosa were extracted with ethanol by cold percolation process and with hot water by heating on a boiling water bath. The respective extracts were pooled, filtered, concentrated at reduced temperature (below $55^{\circ} \mathrm{C}$ ) by rotary evaporation (Büchi, USA), lyophilized (Freezone 4.5; Labconco, USA) under high vacuum $(133 \times 104 \mathrm{mbar})$ at $-40^{\circ} \mathrm{C} \pm 2^{\circ} \mathrm{C}$ to yield the respective ethanolic (EE) and hot water (HWE) extracts, and stored at $40^{\circ} \mathrm{C}$.

2.4. Procedure for Milk Fortification and Sterilization. Different milk combinations with Pueraria tuberosa were prepared by homogenizing pasteurized toned milk with extracts (EE and HWE) of P. tuberosa. For thermal treatment, fortified milk samples and milk controls were added into polypropylene tubes and these tubes were capped. All samples were thermally treated in an autoclave at $15 \mathrm{psi}$ for $5 \mathrm{~min}$. Once heating was completed, lids were tightened while still hot, and tubes were kept upright during observations and storage. Three separate batches of both the fortified milk samples and milk controls were prepared. The $\mathrm{pH}$ values of all combinations were determined for proper evaluation of any significant change in $\mathrm{pH}$ before and after storage.

2.5. Storage Trials, Physical Stability, and pH Tests. Fortified milk samples and milk controls were left at room temperature for $24 \mathrm{hr}$, followed by storage at $2^{\circ} \mathrm{C}$ to $8^{\circ} \mathrm{C}$ for 15 days. Stability profile was checked daily for precipitation profile and $\mathrm{pH}$ by bringing the samples to room temperature. Aliquots of the fortified milk samples and milk controls were observed during this period and sampled after two weeks from each of the three batches, for subsequent analyses. After sampling, the $\mathrm{pH}$ values of all fortified milk sample and milk controls were measured. Following the overall stability check, the analytical profiles of the 1st day and 15th day samples were compared.

2.6. Sample Preparation for HPLC Analysis. Fortified milk samples and milk controls were kept in freezer at lower temperature $\left(-10^{\circ} \mathrm{C}\right)$ for 24 hours, frozen samples then freeze dried by FREEZONE 4.5 lyophilizer, and dried powder weighed to predict the yield from wet mass. Dry lyophilized powder was defatted three times with hexane $(1: 5 \mathrm{w} / \mathrm{v})$ and finally extracted with methanol $(1: 3 \mathrm{w} / \mathrm{v})$ by warming on water bath. Isolated fractions were then dried under reduced pressure and temperature. The dried ethanolic and hot water extracts (EE and HWE) of $P$. tuberosa as well as the dried methanolic extracts of the 1st day and 15th day samples 
were reconstituted in methanol and working solutions of $30 \mathrm{mg} / \mathrm{mL}$ concentrations were made. They were filtered through $0.45 \mu \mathrm{m}$ membrane filters before being subjected to HPLC analysis.

2.7. HPLC Determination of Puerarin. Analyses were performed on a liquid chromatography system (Waters, Milford, MA, USA) with 515 pumps and equipped with an online degasser, a Waters Pump Control Module (PCM), an autosampler 717, a Waters 2996 photodiode array detector (PDA), and Waters Empower software. Separation was carried out using a Supelcosil LC-8-DB column $(250 \times 4.6 \mathrm{~mm}$ i.d.; $5 \mu \mathrm{m}$ pore size) with a guard column $(40 \times 4.6 \mathrm{~mm}$ i.d. $)$ packed with the same material. The column was maintained at $25^{\circ} \mathrm{C}$ throughout the analysis, and detection was at $254 \mathrm{~nm}$. Elution was carried out at a flow rate of $0.8 \mathrm{~mL} / \mathrm{min}$ with water as solvent A and methanol as solvent B using an isocratic elution from $0-10 \mathrm{~min}$ with $90 \%$ of A followed by a gradient elution from $10-15$ min with $90 \%-85 \%$ of $A$, $15-30$ min with $85 \%-70 \%$ of A, 30-37 min with $70 \%-90 \%$ of A, and isocratic from 37 to $45 \mathrm{~min}$ with $90 \%$ of A. Stock solution of puerarin $(1 \mathrm{mg} / \mathrm{mL})$ was prepared in methanol and analysis was carried out under the same working conditions. Each analysis was repeated three times, and the respective retention times were averaged. Peak identification in HPLC analysis was performed by comparison of retention time with reference standard. Quantification of the compounds was achieved by use of calibration plot of the standard solution. The concentrations for the standard used for the calibration curve ranged from $1.0 \mu \mathrm{g}$ to $5.0 \mu \mathrm{g}$ for puerarin. Each run was repeated three times.

2.8. Validation. Validation studies were performed for determining linearity, limit of detection, limit of quantification, repeatability, and percentage recovery. Five concentration points were used to prepare the calibration curve. The calibration plot was prepared by plotting peak area against the amount of puerarin and the regression coefficient $\left(r^{2}\right)$ was calculated. Limits of detection and quantification were determined by calculation of the signal-to-noise ratio. Signalto-noise ratios of approximately $3: 1$ and $10: 1$ were used for estimating the detection limit and quantification limit, respectively. Repeatability was tested by analyzing the puerarin band after application of standard solution to the plate $(n=3)$ and calculating \% RSD. Intraday as well as interday repeatability was estimated. Accuracy was determined using an added external standard. A sample of milk was spiked in triplicate with known quantities of puerarin and the percentage of recovery was calculated. The percentage of recovery rate was established from the experimental response values ((blank + standard) - blank) obtained according to the calibration curves and the real concentration of the standard added.

\section{Results}

3.1. Physical Stability and $p H$ Tests. Stability profile with $\mathrm{pH}$ was checked daily for precipitation profile and $\mathrm{pH}$ by bringing the samples to room temperature. Aliquots of the

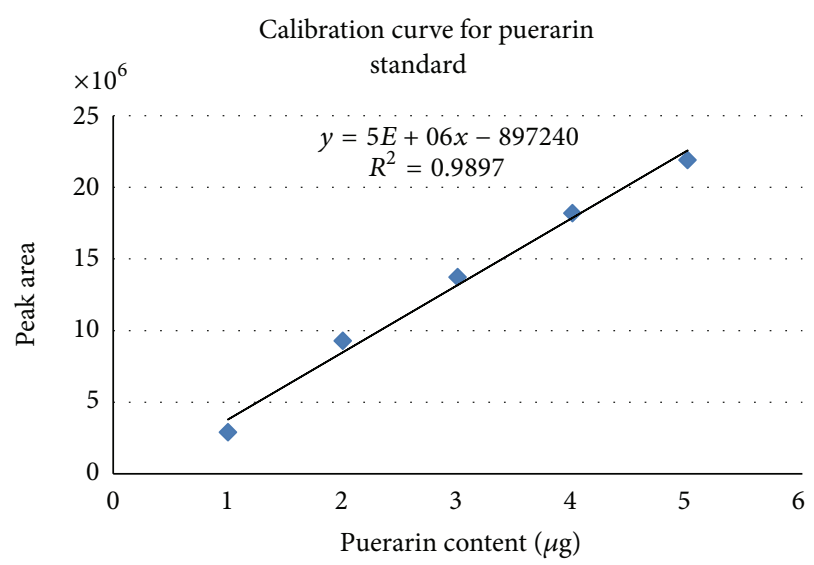

Figure 1: Calibration curve for standard Puerarin.

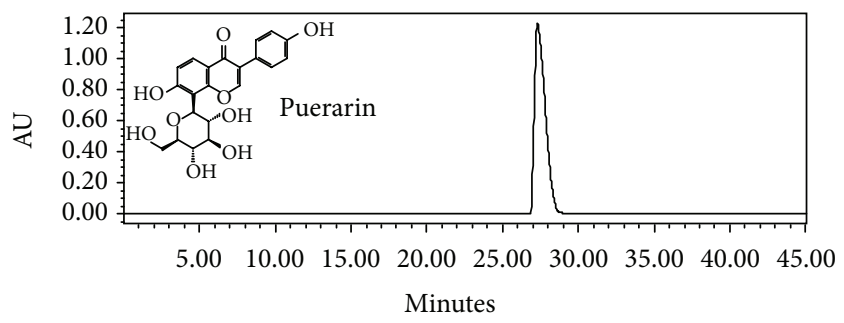

(a)

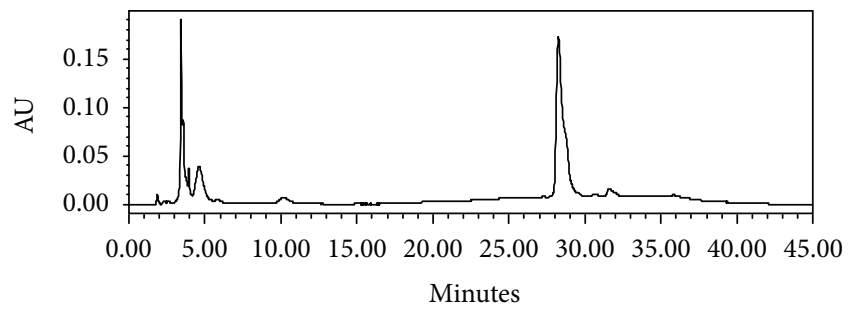

(b)

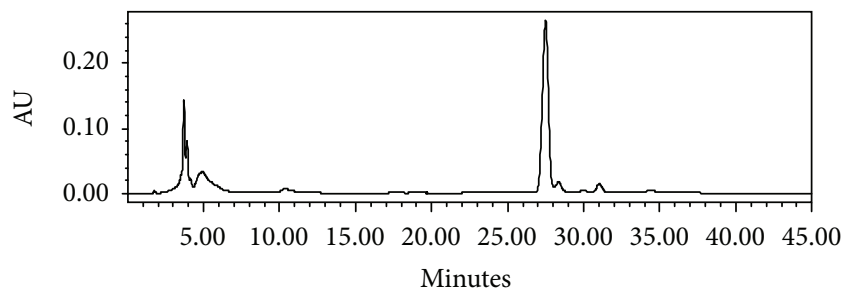

(c)

FIgURE 2: HPLC profiles of fortified milk samples (a) Puerarin standard; (b) methanolic extract of milk $+1.0 \%$ HWE of $P$. tuberosa (1st day); (c) methanolic extract of milk $+1.0 \%$ HWE of $P$. tuberosa (15th day).

fortified milk samples and milk controls were observed during this period. No precipitate formation was observed in the samples. No significant change in the $\mathrm{pH}$ was observed. The observations are tabulated in Table 1 .

3.2. HPLC Determination of Puerarin. To determine the content of puerarin in fortified milk samples, the dried ethanolic and hot water extracts of $P$. tuberosa as well as 
TABLE 1: Stability profile of milk samples.

\begin{tabular}{lcccccrrr}
\hline \multirow{2}{*}{ Milk samples } & \multicolumn{2}{c}{ Day 1 sample } & \multicolumn{2}{c}{ Day 5 sample } & \multicolumn{2}{c}{ Day 10 sample } & \multicolumn{2}{c}{ Day 15 sample } \\
& Precipitate & $\mathrm{pH}$ & Precipitate & $\mathrm{pH}$ & Precipitate & $\mathrm{pH}$ & Precipitate & $\mathrm{pH}$ \\
\hline Milk + 0.5\% EE (w/v) & Absent & 6.50 & Absent & 6.53 & Absent & 6.55 & Absent & 6.58 \\
Milk + 1.0\% EE (w/v) & Absent & 6.46 & Absent & 6.59 & Absent & 6.60 & Absent & 6.69 \\
Milk + 0.4\% HWE (w/v) & Absent & 6.42 & Absent & 6.50 & Absent & 6.59 & Absent & 6.63 \\
Milk + 0.7\% HWE (w/v) & Absent & 6.43 & Absent & 6.45 & Absent & 6.48 & Absent & 6.51 \\
Milk + 1.0\% HWE (w/v) & Absent & 6.42 & Absent & 6.50 & Absent & 6.55 & Absent & 6.59 \\
Milk + 0.01\% puerarin (w/v) & Absent & 6.52 & Absent & 6.60 & Absent & 6.64 & Absent & 6.68 \\
Milk (control) & Absent & 6.61 & Absent & 6.65 & Absent & 6.68 & Absent & 6.71 \\
\hline
\end{tabular}

EE: ethanolic extract of $P$. tuberosa.

HWE: hot water extract of $P$. tuberosa.

TABLe 2: Puerarin content in Indian Kudzu fortified milk samples.

\begin{tabular}{lcc}
\hline Milk sample & $\begin{array}{c}\text { Day 1 sample } \\
(\mathrm{mg} / 10 \mathrm{~mL} \text { fortified milk) }\end{array}$ & $\begin{array}{c}\text { Day 15 sample } \\
(\mathrm{mg} / 10 \mathrm{~mL} \text { fortified milk) }\end{array}$ \\
\hline Milk + 0.5\% EE (w/v) & $2.39 \pm 0.03$ & $2.34 \pm 0.03$ \\
Milk + 1.0\% EE (w/v) & $5.25 \pm 0.04$ & $5.19 \pm 0.16$ \\
Milk + 0.4\% HWE (w/v) & $0.41 \pm 0.02$ & $0.34 \pm 0.04$ \\
Milk + 0.7\% HWE (w/v) & $0.81 \pm 0.03$ & $0.81 \pm 0.03$ \\
Milk + 1.0\% HWE (w/v) & $1.24 \pm 0.05$ & $1.27 \pm 0.02$ \\
Milk + 0.01\% puerarin (w/v) & $1.03 \pm 0.09$ & $0.97 \pm 0.02$ \\
\hline
\end{tabular}

EE: ethanolic extract of $P$. tuberosa.

HWE: hot water extract of $P$. tuberosa.

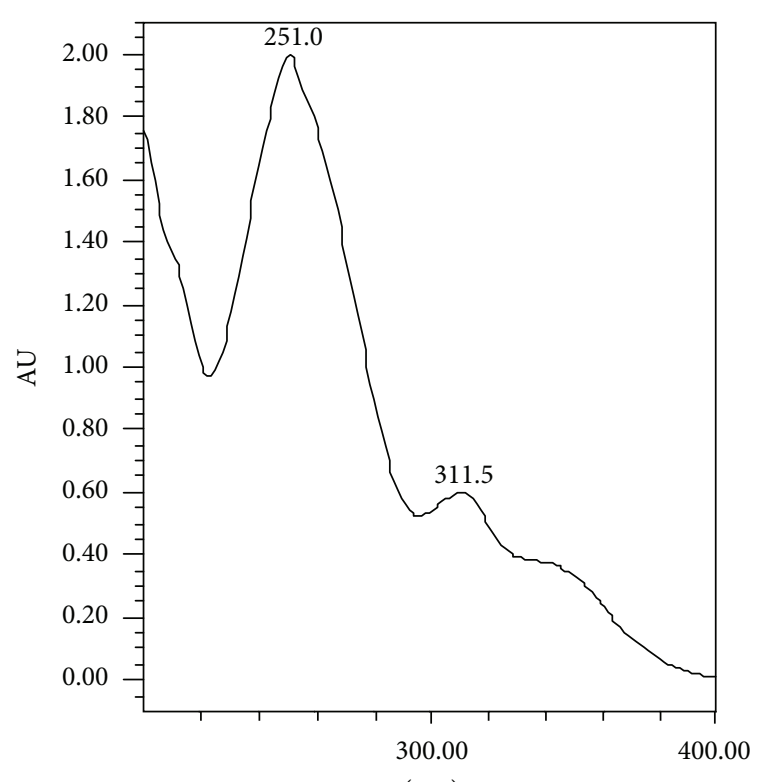

$(\mathrm{nm})$

Figure 3: UV spectrum for Puerarin.

the dried methanolic extracts of the 1st day and 15th day of fortified milk samples were reconstituted in methanol and working solutions of $30 \mathrm{mg} / \mathrm{mL}$ concentrations were made for HPLC analysis. Ten $\mu \mathrm{L}$ of each sample was injected and analysis for puerarin was carried out by using HPLC under the conditions described earlier. Puerarin was monitored at $254 \mathrm{~nm}$. This compound has been of interest due to its many potential health benefits. The calibration curve was plotted for puerarin (Figure 1) and the percentage content of puerarin in different samples was calculated. The ethanolic and hot water extracts of $P$. tuberosa were found to contain $5 \%$ and $1.13 \%$ puerarin, respectively. No peak corresponding to that of puerarin was observed in control milk samples. Figure 2 shows the HPLC chromatograms of the puerarin standard and milk sample fortified with hot water extract of $P$. tuberosa as observed on 1st and 15th day, also monitored at $254 \mathrm{~nm}$. The identity of Puerarin in milk samples was confirmed by comparison of the UV spectra (Figure 3) and retention time with the authentic standard and calculated as mg Puerarin per $10 \mathrm{~mL}$ of fortified milk. Results of the HPLC analysis are presented in Table 2.

3.3. Validation. Linearity, limit of detection, limit of quantification, repeatability, and percentage recovery were studied. The linear range for puerarin was $1.0-5.0 \mu \mathrm{g}$ with a correlation coefficient $\left(r^{2}\right)$ of 0.989 . This correlation coefficient of $>0.950$ was indicative of a good linear relationship between concentration and peak area in the concentration range studied. LOD and LOQ values were $300 \mathrm{ng}$ and $500 \mathrm{ng}$, respectively. Both the intra- and interday R.S.D. were less than $10 \%$ over this range. At the same concentrations, accuracy ranged from 92 to $110 \%$. The high recovery values and a high repeatability indicated a satisfactory accuracy in the method used.

\section{Discussion}

In the present investigation, different herb-milk combinations were prepared by homogenizing pasteurized toned milk 
with extracts (EE and HWE) of $P$. tuberosa. Storage trials for physical stability and $\mathrm{pH}$ monitoring of these fortified milk samples were undertaken and they were analyzed for detection and quantification of puerarin, the major isoflavone C-glucoside present in $P$. tuberosa, through highperformance liquid chromatography using photo diode array detector. A number of studies suggest that Indian Kudzu exhibits antihyperglycemic, antihyperlipidemic, hepatoprotective, antihepatotoxic, and antiimplantation activities [58]. Kudzu has been reported to contain high amounts of phytoestrogenic isoflavones, such as puerarin, daidzein, genistein, and their derivatives [24-26]. These compounds based on the structural similarity to internal estrogen have received much interest for the prevention of menopausal symptoms, osteoporosis, high cholesterol, heart disease, and cancer [27-32]. Also, Kudzu root powder and extract are sold in the United States, United Kingdom, and Australia as a supplement. Kudzu is often used as a single ingredient or in combination with other herbs for relieving hangover, fever, and flu; improving liver function; enhancing detoxification processes; regulating cardiac functions; and aiding weight loss [33].

Milk, being one of the most widely consumed foods in the world, is an ideal vehicle for fortification. However, it is necessary that the samples are stable and the concentration and nature of the herbs/extracts that have been added for fortification do not change on storage. It was observed that there was no precipitate formation and the $\mathrm{pH}$ also did not change during the study period. This indicated that the milk samples were physically stable under the experimental conditions mentioned above. Also, the biomarker used for chemical analysis was puerarin, which is the major constituent of Kudzu. HPLC analysis results showed that the puerarin content can directly be a measure of the amount of ethanolic or hot water extracts of $P$. tuberosa added for fortification. Also there was no significant change in the content of puerarin during the study period, thereby indicating the chemical stability of the samples. These studies will be useful for developing milk nutraceuticals fortified with Indian Kudzu which has the potential to be included as an ingredient in health and functional foods.

\section{Conclusions}

A modern lifestyle is fast paced and mostly hurried where most people battle with time poverty. As a result, it is often difficult to find the time and energy to eat correctly and supply your body with the correct type of nutrition. On top of that, an individual's health and nutrition needs do also change throughout his or her life. It is for this reason that development of functional foods and nutraceuticals with special health-promoting benefits is the need of the day. Herbal extracts in all their forms possess arguably the greatest potential for innovative functional food products. There are many companies already capitalizing on growing consumer acceptance of food and beverages containing herbal extracts [2] although the use of these extracts in milk and milk products is quite a recent development. Milk is also one of the most widely consumed foods in the world and is an ideal vehicle for fortification with these nutraceuticals. Also, numerous nutraceutical combinations have entered the international market through exploration of ethnopharmacological claims made by different traditional practices. These foods or nutraceuticals construct a health-promoting, diseasepreventing diet with protective substances. The rich nutrient food intake will provide maximum protection against not only infections, asthma, and allergies, but also against heart disease and cancer in adulthood. However, before the full market potential can be realized, the consumers need to be assured of the safety and efficacy of functional foods. Future research will focus on mechanisms by which food components such as phytochemicals positively affect health, and whether these components work independently or synergistically.

\section{Conflict of Interests}

The authors do not have any conflict of interests in this paper.

\section{Acknowledgments}

The authors are grateful to the Director, CSIR-National Botanical Research Institute, Lucknow, for providing the research facilities to carry out this work. This work was supported by the National Agriculture Innovation Project (Component 4: Basic and Strategic Research Subproject Code C30029), Indian Council of Agricultural Research, New Delhi, India.

\section{References}

[1] P. Coppens, L. Delmulle, O. Gulati et al., "Use of botanicals in food supplements: regulatory scope, scientific risk assessment and claim substantiation," Annals of Nutrition and Metabolism, vol. 50, no. 6, pp. 538-554, 2007.

[2] C. Rowan, "Extracting the best from herbs," Food Engineering International, vol. 25, pp. 31-34, 2000.

[3] The Ayurvedic Pharmacopoeia of India-Part I, vol. 5, Ministry of Health and Family Welfare, New Delhi, India, 1st edition, 2006.

[4] G. S. Pandey and K. C. Chunekar, in Bhav Prakash Nighantu, V. Kand, Ed., vol. 1, pp. 388-389, ChaukambhaVidya Bhavan, Varanasi, India, 1998.

[5] L. F. Hsu, M. I. Liu, H. D. Kuo, C. W. Chen, C. H. Su, and T. J. Cheng, "Antihyperglycemic effect of Puerarin in streptozotocin-induced rats," Journal of Natural Products, vol. 66, pp. 788-792, 2003.

[6] Y. S. Tanwar, S. Goyal, and K. G. Ramawat, "Hypolipidemic effects of tubers of Indian Kudzu (Pueraria tuberose)," Journal of Herbal Medicine Toxicology, vol. 2, no. 1, pp. 21-25, 2008.

[7] R. S. Gupta, R. Sharma, and A. Sharma, "Antifertility effects of Pueraria tuberose root extract in male rats," Pharmaceutical Biology, vol. 42, no. 8, pp. 603-609, 2004.

[8] S. Shukla, S. Jonathan, and A. Sharma, "Protective action of butanolic extract of Pueraria tuberosa DC against carbon tetrachloride induced hepatotoxicity in adult rats," Phytotherapy Research, vol. 10, no. 7, pp. 608-609, 1996. 
[9] A. K. Gupta, Quality Standards of Indian Medicinal Plants, ICMR, New Delhi, India, 2003.

[10] S. S. Handa and M. K. Kaul, "Recent development of some natural products," in Supplement To Cultivation and Utilization of Medical Plants, S. S. Handa and M. K. Kaul, Eds., pp. 53-96, CSIR, RPL, Jammu-Tawi, 1996.

[11] R. A. Khan, P. K. Agarwal, and R. S. Kapil, "Puetuberosanol, an epoxychalcanol from Pueraria tuberosa," Phytochemistry, vol. 42, pp. 242-244, 1996.

[12] B. S. Joshi and V. N. Kamat, "Tuberosin, a new pterocarpan from Pueraria tuberosa DC," Journal of the Chemical Society, Perkin Transactions 1, pp. 907-911, 1973.

[13] A. Koul and G. Sumbali, "Detection of zearalenone, zearalenol and deoxynivalenol from medicinally important dried rhizomes and root tubers," African Journal of Biotechnology, vol. 7, no. 22, pp. 4136-4139, 2008.

[14] N. Torres, I. Torre-Villavazo, and A. R. Tovar, "Regulation of lipid metabolism by soya protein and its implications in diseases mediated by lipid disorder," The Journal of Nutritional Biochemistry, vol. 17, pp. 365-373, 2006.

[15] H. Liu, "Effects of temperature and common ions on binding of Puerarin to BSA," Journal of Solution Chemistry, vol. 38, pp. 1071-1077, 2009.

[16] X. R. G. Juqun, "Interactions of puerarin with micelles: pKa shifts," Journal of Solution Chemistry, vol. 37, pp. 107-118, 2008.

[17] L. H. Riihimäki, M. J. Vainio, J. M. S. Heikura, K. H. Valkonen, V. T. Virtanen, and P. M. Vuorela, "Binding of phenolic compounds and their derivatives to bovine and reindeer $\beta$ lactoglobulin," Journal of Agricultural and Food Chemistry, vol. 56, no. 17, pp. 7721-7729, 2008.

[18] S. P. Digambar, R. R. B. Singh, S. Kapila, S. Arora, S. Rastogi, and A. K. S. Rawat, "Immunomodulatory and antioxidative potential of herb (Pueraria tuberosa)-milk model in mice," International Journal of Dairy Technology, vol. 66, pp. 202-206, 2012.

[19] N. Pawar, K. Gandhi, A. Purohit, S. Arora, and R. R. B. Singh, "Effect of added herb extracts on oxidative stability of ghee (butter oil) during accelerated oxidation condition," Journal of Food Science and Technology, 2012.

[20] X. P. Song, P. P. Chen, and X. S. Chai, "Effects of puerarin on blood pressure and plasma renin activity in spontaneously hypertensive rats," Zhongguo Yao Li Xue Bao, vol. 9, pp. 55-58, 1988.

[21] D. Li, S. H. Park, J. H. Shim et al., "In vitro enzymatic modification of puerarin to puerarin glycosides by maltogenic amylase," Carbohydrate Research, vol. 339, no. 17, pp. 2789-2797, 2004.

[22] F. Lin, B. Xie, F. Cai, and G. Wu, "Protective effect of Puerarin on $\beta$-amyloid-induced neurotoxicity in rat hippocampal neurons," Arzneimittelforschung, vol. 62, no. 4, pp. 187-193, 2012.

[23] K. Maji, N. Maity, P. Banerji, and D. Banerjee, "A validated RPHPLC-UV method for quantitative determination of puerarin in Pueraria tuberose DC tuber extract," Pharmaceutical Methods, vol. 3, pp. 79-83, 2012.

[24] Y. Lu, T. Zhang, J. S. Tao, and L. Y. Xu, "Pharmacokinetics of pueraria for intranasal on spray in rabbits," Journal of Chinese Medicinal Materials, vol. 30, no. 9, pp. 1102-1105, 2007.

[25] Y. M. Zheng, X. Y. Xu, and S. Q. Fu, "Study on data analysis method of Kudzu root total flavone finger-print," China Journal of Chinese Materia Medica, vol. 30, pp. 70-71, 2005.
[26] Q. Chang, L. Sun, R. H. Zhao, M. S. S. Chow, and Z. Zuo, "Simultaneous determination of ten active components in traditional Chinese medicinal products containing both gegen (Pueraria iobata) and danshen (Salvia miltiorrhiza) by highperformance liquid chromatography," Phytochemical Analysis, vol. 19, no. 4, pp. 368-375, 2008.

[27] D. M. Tham, C. D. Gardner, and W. L. Haskell, "Potential health benefits of dietary phytoestrogens: a review of the clinical, epidemiological, and mechanistic evidence," Journal of Clinical Endocrinology and Metabolism, vol. 83, no. 7, pp. 2223-2235, 1998.

[28] K. D. R. Setchell and A. Cassidy, "Dietary isoflavones: biological effects and relevance to human health," Journal of Nutrition, vol. 129, no. 3758, pp. 758S-767S, 1999.

[29] K. Yanagihara, A. Ito, T. Toge, and M. Numoto, "Antiproliferative effects of isoflavones on human cancer cell lines established from the gastrointestinal tract," Cancer Research, vol. 53, no. 23, pp. 5815-5821, 1993.

[30] K. K. Hintz and J. Ren, "Phytoestrogenic isoflavones daidzein and genistein reduce glucose-toxicity-induced cardiac contractile dysfunction in ventricular myocytes," Endocrine Research, vol. 30, no. 2, pp. 215-223, 2004.

[31] X. P. Song, P. P. Chen, and X. S. Chai, "Effects of puerarin on blood pressure and plasma renin activity in spontaneously hypertensive rats," Acta Pharmacologica Sinica, vol. 9, no. 1, pp. 55-58, 1988.

[32] L. P. Yan, S. W. Chan, A. S. C. Chan, S. L. Chen, X. J. Ma, and H. $\mathrm{X} . \mathrm{Xu}$, "Puerarin decreases serum total cholesterol and enhances thoracic aorta endothelial nitric oxide synthase expression in diet-induced hypercholesterolemic rats," Life Sciences, vol. 79, no. 4, pp. 324-330, 2006.

[33] K. H. Wong, G. Q. Li, K. M. Li, V. Razmovski-Naumovski, and K. Chan, "Kudzu root: traditional uses and potential medicinal benefits in diabetes and cardiovascular diseases," Journal of Ethnopharmacology, vol. 134, pp. 584-607, 2011. 


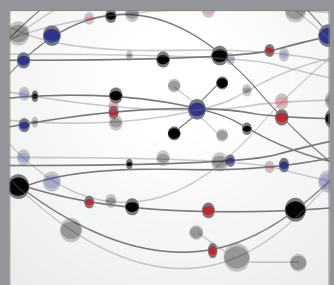

The Scientific World Journal
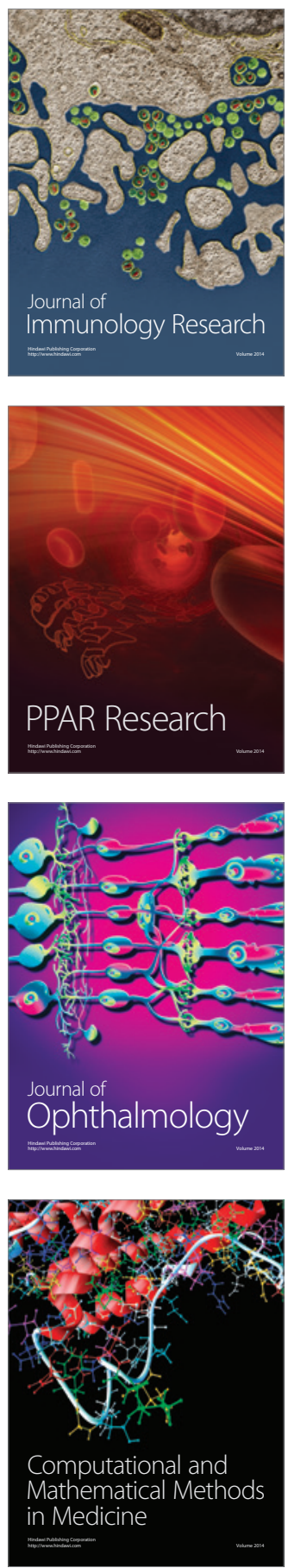

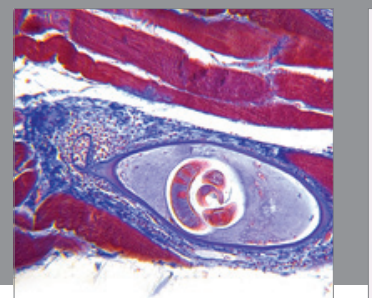

Gastroenterology

Research and Practice
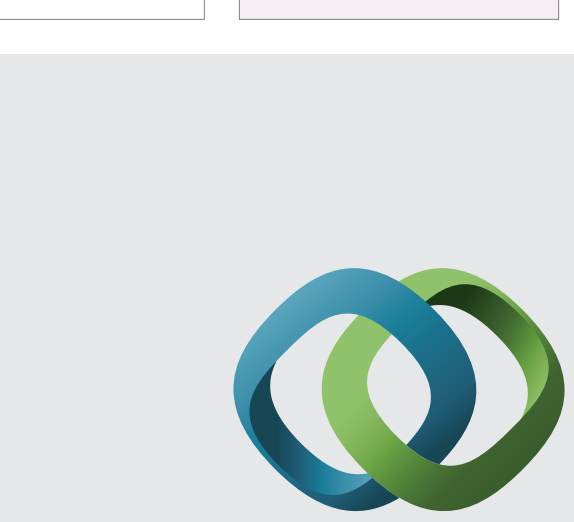

\section{Hindawi}

Submit your manuscripts at

http://www.hindawi.com
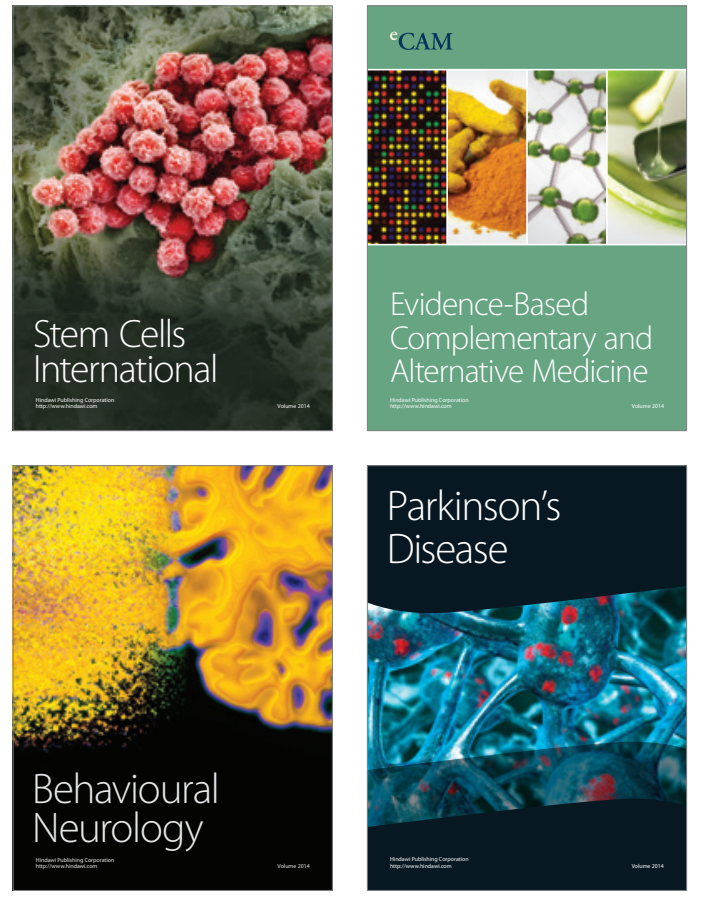
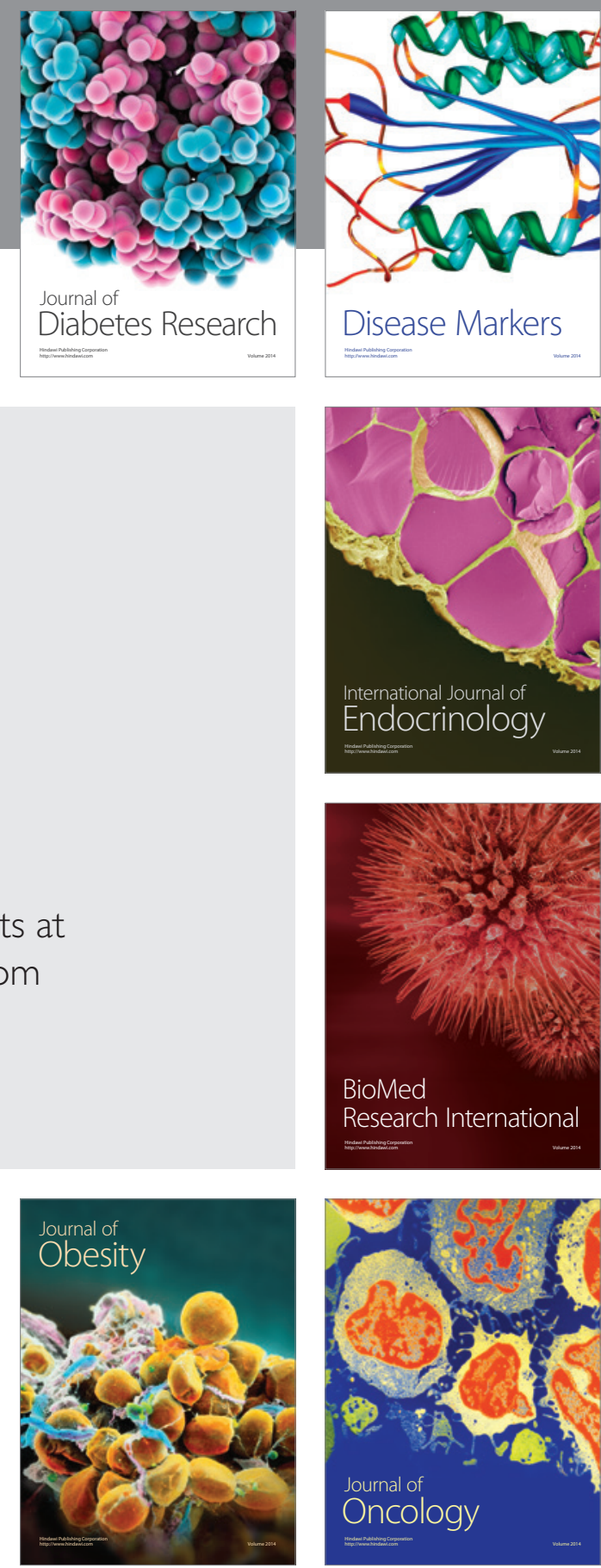

Disease Markers
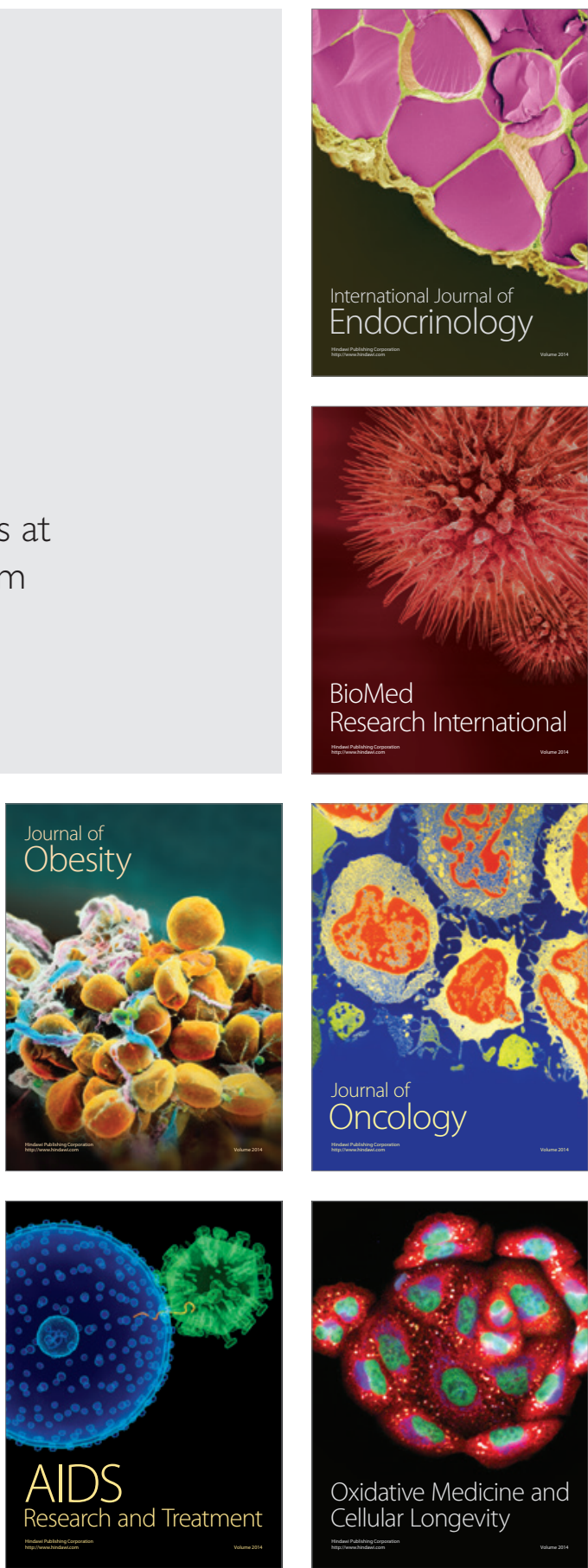